\title{
Effect of sowing method, soil moisture and temperature on establishment from coated grass seed
}

D. SCOTT', W.J. ARCHIE' and R.J.M. HAY ${ }^{2}$

1 AgResearch Grasslands, PO Box 60, Lincoln 2 AgResearch Grasslands, Private Bag, Palmerston North

\begin{abstract}
Two field trials showed up to $60 \%$ greater establishment from surface-sown coated ryegrass seed compared with bare seed. Coating had a minimal effect on drilled seed. Multiple sowings over two seasons showed that the increase in establishment from coated seed relative to bare seed was only weakly related to temperature and soil moisture. The trend was for greater establishment from coated seed at lower mean establishment rates and higher soil temperature.
\end{abstract}

Keywords Dactylis glomerata, grass seed coating, environmental interactions, Lolium perenne

\section{Introduction}

Where cultivation or direct drilling is not possible it is necessary to investigate ways to improve the generally lower establishment of grass from broadcast sowings. Coating of grass seed is one option that has been considered.

Earlier work on the establishment of broadcast coated grass seed has shown occasional large effects (x 4-6 greater establishment compared with bare seed), but the effect has been highly inconsistent between similar trials at different sites or in different seasons (Vartha \& Clifford 1973; Scott \& Hay 1974; Zaller 1974; Scott 1975; Dowling 1978; Lee et al. 1990). Glasshouse and laboratory experiments have shown that the coating effect is probably related to improved moisture relationships at the germination and early seedling stage (Dowling et.al. 1971; Scott \& Hay 1974; Scott 1975). Thus the coating effect would probably be. manifested under marginal field moisture conditions, but appropriate field experiments have not been done. The first experiment described here used multiple sowings over two seasons to relate the relative success of coated and bare seed to soil moisture and temperature conditions from time of sowing to initial seedling establishment.

Most investigations on grass seed coating have been with broadcast sowings, and little is known of its advantages or disadvantages in drilling. A comparison was made in two experiments.

\section{Methods}

The first experiment was at Lincoln on a uniform area $(50 \times 50 \mathrm{~m})$ of cultivated Wakanui silt loam with a moisture content of $28 \%$ at field capacity and $11 \%$ at wilting point. Commercial 1: 1 phosphate coat; seed (w/ w) perennial ryegrass and cocksfoot seed were sown either drilled (10 mm depth) or surface broadcast with a Stanhay precision seeder. Forty-six sowings were made from August to December 1976. March to April and October to December 1977. Strips $10 \mathrm{~m}$ long of each treatment were seeded on each occasion with four $0.5-\mathrm{m}$ sample strips marked for seedling counts prior to emergence.

Plots were scored at weekly intervals up to 8 weeks after sowing with the final analysis being confined to scores at the 2-leaf and I-week stage. Individual results were adjusted for seeding rates. and coating treatments expressed as ratio of the corresponding bare seed treatments. It was thoseratios that were analysed. Four 5-mm

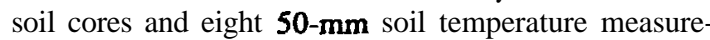
ments were taken near midday from the perimeter of the trial area on each of the sowing or sampling dates to define the gravimetric soil moisture and temperature conditions. The combined results of all sowings of both species of surface and subsurface sowings, and of the assessment at two stages, were subjected to covariance analysis withlinearrelationships with soil moisture, soil temperature and with their interaction during the establishment period.

A second experiment at Gore on a Waimumu silt loam compared three types of coatings on the establishment of ryegrass seed (1:1 phosphate : seed, 1:1:1 phosphate : nitrogen : seed and c. $\mathbf{0 . 5} \mathbf{g}$ pellets containing c. 5 seeds together with phosphate fertiliser and pulped wood filler). Plots were either drilled (10 $\mathrm{mm}$ depth) or broadcast in spring on to a ryegrass sward, recently sprayed with paraquat. in a split plot design. Measurements for seedling density were made at 14 and 28 days in 3-m strip quadrats.

\section{Results and discussion}

The experimental treatments and environmental covariatesexplainedonly $15 \%$ of the variation in the establish- 
ment ratios of coated to bare seed of ryegrass and cocksfoot for the combiied data in the first experiment. The only significant effects were for species, sowing methods, soil temperature and their interaction (Table la). There was no advantage of seed coating for the slower germinating cocksfoot in either situation. There was an advantage of coating for the faster germinating ryegrass seed, thii being significantly greater for broadcast as compared with drilling. Eleven per cent of observations had coating to bare ratio exceeding 2.0.

There was a significant effect of coating for broadcast ryegrass seed in the second experiment (Table lb). The coated to bare establishment ratio also increased with coat weight ( $\mathrm{P}$ c 0.10). Additional analysis showed there was also a marginally significant trend for the coating effect to increase towards the second sampling, the trend being greater for the higher coating ratios.

Table 1 Establishment ratio (coated/bare) of broadcast and drilled sowings of ryegrass and cocksfoot seed.

\begin{tabular}{ccc}
\hline & \multicolumn{2}{c}{ Coated/bare Ratio } \\
\hline & B r adcast & Drilled \\
(a) 1 coat type (1:1) 2 species & & \\
ryegrass & 1.60 & 1.19 \\
cocksfoot & 1.10 & 1.12 \\
& L S D 5 $\%=0.30$ \\
(b) 3 coat types: ryegrass & \multicolumn{1}{c}{1.12} & 1.00 \\
$1: 1$ coat & 1.27 & 1.05 \\
$1: 1: 1$ coat & 1.51 & 1.35 \\
Dellot & LSD 5\% $=0.13$ \\
\hline
\end{tabular}

Themultiple sowings achieved a range of soil moisture and temperature combinations in the first experiment, but their effects on broadcast-sown cocksfoot seed was not significant when considering temperature and moisture classes. The most pronounced effect of environmental covariates was for surface-sown perennial ryegrass at the 8-week stage. Response surface analysis indicated that the trend, apart from two exceptional observations, was for a coated to bare ratio was at higher mean soil temperature even the period and lower mean percentage establishment. Figure 1 shows this in the scattergram of the base data. However, the relationship was weak, accounting for only $24 \%$ of thevariation, and the figures show two observations with a large coating response.

These effects are contrary to the expected effect on initial moisture uptake of coating (Dowling et al. 1971; Scott 1975). A similar trial has been reported by Dowling (1978) in which there were 29 broadcast sowings over two seasons of coated and bare tall fescue and phalaris seed. He obtained a mean establishment ratio of

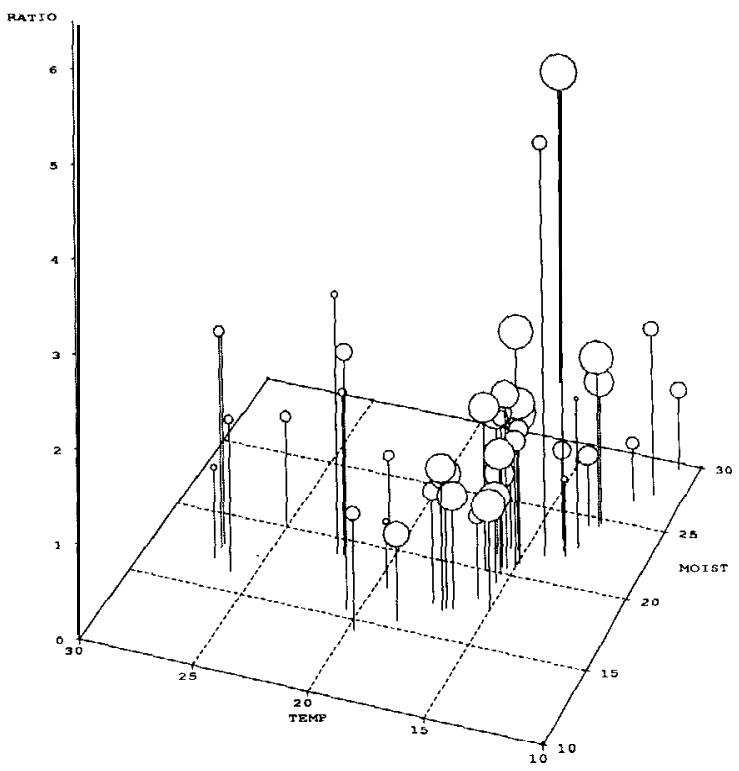

Figure 1 Effect of soil conditions at time of sowing (soil temperature left to right, soil moisture - front to back) on the establishment ratio (seedling from coated seed relative to bare seed at 8 weeks - vertical axis) in multiple broadcast sowings of ryegrass seed. Sii of symbol proportional to mean percentage establishment.

1.32 for tall fescue and 0.92 for phalaris when comparing a 2:1 inert coating with bare seed. In both species there was depression with nutrient coating containing soluble salts (sodium molybdate and potassium sulphate), confirming earlier reports (Scott. 1975; Scott \& Archie, 1978). Re-analysis of Dowling's published data (1978) showed that the trend was for the establishment ratio to increase with decreasing soil moisture rather than with temperature.

Both experiments showed the beneficial effects of coating on establishment of ryegrass but that the increase was small, so that consideration must be given to wst of coating, relative to increasing rates of bare seed.

The conclusion from this work is that phosphate grass seed coating confers no advantage in drill sowings. While the indications are that coating of grass seed is beneficial for broadcast sowings in field situations, the exact conditions under which it is beneficial are still insufficiently defied.

\section{REFERENCES}

Dowling, P.M. 1978. Effect of seed coating on the germination, establishment, and survival of oversown pasture species at Glenn Innes, New South Wales. New Zealand journal of experimental agriculture, 6: 161-66. 
Dowling, P.M.; Clements, R. J.; McWilliam, J.R. 1971. Establishment and survival of pasture species from seed sown on soil surface. Australian journal of agricultural research 22: 61-74.

Lee. H.; Kim. H.K.; Kim, C.H. 1990. Studies on establishment of oversown pasture see. II Effect of coating materials on germination, establishment and yield of pasture species. Journal of the Korean Society of Grassland Science IO: 10-14 [Herbage Abstracts].

Scott, D. 1975. Effect of seedcoating on establishment. New Zealand journal of agricultural research 18: 59-67.

Scott, D. ; Archie, W.J. 1978. Sulphur, phosphate and molybdenum coating of legume seed. Ibid 21: 64349.

Scott, D.; Hay, R.J.M. 1974. Some physical and nutritional effects of seed coating. Proceedings of 12th International Grassland Congress l(2): 523-31.

Soil Bureau, 1968. General survey of the soils of South Island, New Zealand. Soil Bureau Bulletin 27: 404 pp.

Vartha, E.W.; Clifford P.T.P. 1974. Effects of seed coatings on establishment and survival of grasses. surface sown on tussock grasslands. New Zealand journal of experimental agriculture 1. 39-43.

Zaller. S. 1974. Aerial seeding on non-arable land in Victoria. 12th International Grassland Congress (pre-circulated paper). 